\title{
Complex Post Traumatic Stress Disorder Symptoms Among Midlife to Older Female Survivors of Intimate Partner Violence
}

Nikki Carthy, Daisy Best, Victoria Heckels, Weber, Leah, Judith Eberhardt Department of Psychology, School of Social Sciences, Humanities and Law, Teesside University, UK.

\section{Author Note}

Nikki Carthy http://orcid.org/0000-0001-9677-0066

Judith Eberhardt http://oricd.org/0000-0003-0745-178X

Leah Weber took part in this research as an undergraduate student research assistant and is now at EVA Women's Aid, UK.

Daisy Best is now at North Yorkshire Psychological Therapies, UK.

We have no conflicts of interest to note.

Correspondence concerning this article should be addressed to Dr Nikki Carthy, Department of Psychology, School of Social Sciences, Humanities and Law, Teesside University, Campus Heart, Tees Valley, TS1 3BX, UK. Email: N.Carthy@tees.ac.uk (C) 2022, American Psychological Association. This paper is not the copy of record and may not exactly replicate the final, authoritative version of the article. Please do not copy or cite without authors' permission. The final article will be available, upon publication, via its DOI: $10.1037 /$ tra0001238 


\title{
COMPLEX POST TRAMATIC STRESS DISORDER SYMPTOMS AMONG MIDLIFE TO OLDER FEMALE SURVIVORS OF INTIMATE PARTNER VIOLENCE
}

\begin{abstract}
Objective: Survivors of intimate partner violence are exposed to prolonged and repeated trauma due to the methods of control associated with abuse, however, do not always seek help from trauma-focused service provision. Despite links between complex post-traumatic stress disorder and partner violence, research has not explored how symptoms may be presented within the stories of abuse and the clinical implications of this. The aim was to explore the narratives of intimate partner violence and uncover how aspects of complex posttraumatic stress disorder may be present. Method: The stories from thirteen women with a mean age of 52.3 years were explored using thematic analysis. Results: Across the survivors' stories, four themes with associated sub-themes were uncovered: 1) difficulties in affect regulation, 2) belief systems that erode self-determination, 3) managing the threat response, and 4) difficulties in sustaining relationships. The findings suggest underlying symptoms of complex trauma were present. Presentations of symptoms associated with complex posttraumatic stress disorder demonstrates a need for therapeutic practitioners to be more aware of the prevalence of this for those who have experienced relational abuse and the implications for therapeutic interventions and engagement. Conclusions: Exploring traumatic experiences from the perspectives of survivors is an important way of understanding the impacts and consequences on the survivor and their adjustment beyond abuse, moving from a symptomatic lens to an approach of trauma journey exploration.
\end{abstract}

Key words: trauma, intimate partner violence, domestic abuse, older women, complex post-traumatic stress disorder

\section{Clinical Impact Statement}


This study addresses the links between complex post-traumatic stress disorder and intimate partner violence and the consequences for mental health and quality of life among midlife and older female survivors. The findings suggest that some symptoms of complex trauma can be broadly found within the survivors' stories. Results of the study provide insights into identifying aspects of such traumatic stressors that therapeutic practitioners should be vigilant to in clinical practice.

\section{Introduction}

Trauma research has gained momentum within the academic and clinical literature, which has impacted positively on clinical treatment and practice. Most widely known are the formulations of post-traumatic stress disorder (PTSD), which were derived from observations of survivors of combat and disaster and more recently in rape survivors. A diagnosis of PTSD has since been criticised for not capturing the complex symptomology of trauma responses such as changes to personality and vulnerability to repeated harm, that have been observed in survivors of long-term and prolonged abuse (Miller \& Resick, 2007). The notion of complex trauma, extending beyond the traditional PTSD diagnosis, has been discussed in academic and clinical literature for several years, despite only becoming recognised clinically in 2018 . However, complex trauma was not defined within the most recent version of the Diagnostic and Statistical Manual (DSM-5) and was only recently defined as complex post-traumatic stress disorder (CPTSD) within the International Classification of Disorders (ICD-11) (World Health Organisation [WHO], 2018).

The ICD-11 criteria for CPTSD include a traumatic event or number of events that usually occur repeatedly, cumulatively, and that are horrific or threatening in nature (Courtois, 2004). Escape is considered difficult or impossible and examples of traumatic events include intimate partner violence (IPV), childhood sexual or physical abuse which has occurred repeatedly, torture, and genocide (WHO, 2018). Experiencing long-term and 
repeated traumatic events such as IPV, is different to experiencing one, isolated incident. In both instances' PTSD is often diagnosed. The core symptoms of PTSD included in this diagnostic category are: “...re-experiencing of the trauma in the here and now, avoidance of traumatic reminders and persistent sense of current threat...” (Karatzias et al., 2018, p.2). Despite clinical support for the diagnosis of PTSD for one traumatic incident, van der Kolk (2000) argues that there are many patients seeking clinical treatment who have endured multiple traumatic experiences. The range of psychological responses to trauma is not always covered in the PTSD definition (van der Kolk, 2000). Survivors of domestic violence are more likely to be subjected to repeat victimisation than victims of other crimes (Walby \& Allen, 2004). Being aware of the impact of long-term and prolonged abuse and the limitation of a PTSD diagnosis should be considered when working clinically with survivors of IPV.

Complex trauma occurs because of multiple traumatic events experienced across the lifespan or within adulthood only (Lawson, et al. 2013). To meet the criteria for CPTSD, PTSD symptomology must be present in addition to difficulties with affect regulation, a diminished self-concept, and feeling defeated or worthless. This would be accompanied by deep and pervasive feelings of shame, guilt or failure and difficulties in sustaining relationships and attachments to others (Sweeney \& Taggart, 2018; WHO, 2018). Howard et al. (2010) identified complex traumatic stress syndrome as extending beyond the PTSD cluster including changes in the IPV survivor such as their attitude towards the self, the perpetrator, relationships, and personal beliefs. This change in attitude can have a detrimental effect on mental health and well-being. Trauma-informed care presents a paradigm shift from 'what is wrong with you?' to a 'what has happened to you?' approach (Johnstone \& Boyle, 2018; Sweeney \& Taggart, 2018). Conceptualising the client through a trauma lens can assist the clinician in being more empathic, impacting positively on treatment pathways as well as the therapist's own personal reactions. 
CPTSD overlaps with other mental health presentations. Early trauma alongside person-level variables influences longer term mental health difficulties including personality problems, therefore a more holistic, phenomenologically based, framework for assessment of the person is needed (Briere \& Spinazzola, 2005). Clinical and therapeutic professionals often lack knowledge of CPTSD presentations across therapeutic practice, which can be problematic in establishing a diagnosis (Hopchet et al. 2017). Many of the characteristics of CPTSD have similar associations with borderline personality disorder (BPD) such as emotional lability, relational instability, impulsivity, unstable sense of self, and behaviours associated with self-harm (Ford \& Courtios, 2014). Kulkarni (2017) highlights that, pre-ICD11, many people who were assessed within psychiatric services were diagnosed with BPD when a CPTSD diagnosis would be more appropriate. Kulkarni (2017) states those who have "suffered prolonged and severe interpersonal trauma" (p.334) would fit the CPTSD diagnosis as it emphasises 'exposure to traumatic stress' (p.334) which is not a criterion within the DSM-5 for a BPD diagnosis. Therefore, the predisposing and precipitating factors are important to understanding the client's trauma journey and the impact of this on their psychological adjustment which is supported by The Power Threat Meaning Framework (PTMF, Johnstone \& Boyle, 2018). This is a meta-framework seeking to contextualise rather than pathologise emotional distress. Whilst diagnostic criteria may be helpful for some in being able to observe common responses to difficult experiences, the PTMF emphasises subjective experiences. Our study explored the narratives provided by mid-life and older women about their experiences of long-term IPV and this framework allows for a link between the subjective experiences of survivors and the theoretical positions and clinical practices of psychologists and therapists. The PTMF is positioned alongside the language of diagnostic criteria (CPTSD) whilst recognising that this diagnostic language is used as a means of making sense of survivors' experiences rather than to label those experiences. 
Domestic and intimate partner violence is defined as a single or several incidents, which include behaviour that is controlling, coercive, or threatening. Violence or abuse includes psychological, sexual, physical, financial, or emotional and this can occur for those who are family members or present and past intimate partners (Home Office, 2015). Prolonged and repeated trauma occurs when the survivor is in a state of captivity (Herman, 1992). This is often the case in abusive relationships due to a power imbalance and the survivor being under the control of the perpetrator via physical, psychological, social, or financial force. The abuse may occur repeatedly and often escalates over time. Some survivors develop depression, suicidal ideation, self-harm, PTSD, medically unexplained somatic complaints, sleep disorders, or anxiety (WHO, 2020). Dokkedahl et al. (2021) found psychological violence to be a strong predictor of mental health problems among IPV survivors. Moreover, in a recent review of the literature psychological abuse was found to be the most reported form of abuse among women 45 and older (Pathak, et al. 2019). However, research into psychological abuse is still in its infancy. IPV survivors are at risk of developing more severe symptoms of PTSD when negative social reactions to disclosures are received (Dekel et al., 2019; Schackner et al., 2017). PTSD criteria alone do not account for

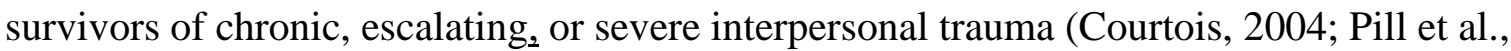
2017) and research investigating complex trauma among women surviving IPV is limited (Pill et al., 2017).

Many mid-life and older adults who have experienced chronic trauma have been in abusive relationships over prolonged periods of time and are more likely to stay in a violent relationship (Pathak et al., 2019). Barriers to help-seeking in mid-life to older adults include internal factors such as self-blame, protection of others, and hopelessness, as well as external factors such as how others respond to disclosures (Beaulaurier et al., 2008; Carthy \& Taylor, 2018). To ensure safety mental health needs are overlooked and more research is required to 
understand the role of trauma for survivors of IPV (Pill et al., 2017). Despite CPTSD having been linked to IPV (Litvin et al., 2017; Pill et al., 2017), research is needed to consider the clinical implications for this cohort of women.

This is the first exploratory study aiming to identify aspects of CPTSD in the stories of an older cohort of female IPV survivors. Due to the complexities of IPV, those working therapeutically with survivors may miss important aspects of their story that would lead to recognition of CPTSD. Midlife and older females are a survivor group who have been neglected in the IPV literature generally. Furthermore, complex trauma is a new field in terms of diagnosis; therefore, there are gaps in relation to the applicability of the criteria to specific populations. The current study aimed to address those gaps by exploring what CPTSD is within this context, whether symptoms were present in a cohort of mid-life to older female survivors of IPV, and how practitioners could use this knowledge to develop their therapeutic working practice.

\section{Method}

\section{Design}

A narrative approach was implemented to allow an account of what happened through participants' own subjective lens, the focus being on what is important and meaningful to the narrator. Narrative psychology focuses on the lived experience of the individual and links what we say about ourselves with our cognitions and behaviours (Crossley, 2000). Responses to trauma should include understanding of past and current events and circumstances as well as the impacts and consequences of this on people's lives so that it can be understood in the context of the individual's own interpretations and experience (Substance Abuse and Mental Health Services Administration, 2014).

\section{Data and procedure}


Thirteen women with a mean age of 52.3 years, took part in the research. Eleven participants identified as heterosexual, two did not disclose sexuality. Eleven participants identified as White British, and two as British Asian. All but one participant were parents, and none were living with their children who were all 18 years and over. Two participants were employed at the time of the study.

The violent partner for all participants was male. Ten participants had one violent partner, three had two or more violent partners. All participants disclosed experiences of physical violence and control. Eight participants were survivors of childhood abuse. At the time of interview, all participants were receiving various levels of accommodation, community-based, or counselling support. The presence of psychiatric symptoms was not assessed in the sample.

Ethics clearance was granted by the ethics review board of the authors' institution. Participants were recruited from third-sector domestic violence services from which they were receiving support. Information was given to them by the Manager of the service and they were provided with contact details to express their interest. All those willing to participate, who met the inclusion criteria (over 45 years of age, and having survived IPV), and provided informed consent, took part. All interviews were conducted by a female member of the research team experienced in qualitative interviewing, using a semi-structured interview schedule. The interviews were collected to explore the stories of midlife and older female survivors' of IPV and were not collected for the purposes of exploring CPTSD, therefore the study made use of secondary data. Therefore, we focused our exploration of the data on the women's journey and trauma-related responses.

\section{Analysis}

Data were analysed using a deductive thematic analysis with focus on semantic themes using Braun \& Clarke's (2006) 6-step process. Three researchers, including one 
clinician, coded half of the interviews independently, by reading and re-reading the transcripts (step 1), generating initial codes (step 2), and identifying themes (step 3). All three reviewed and agreed the initial themes (step 4). Two researchers, who were not clinicians, coded the rest of the interviews independently, following steps 1-3. Once this stage was complete, all researchers reviewed and defined the final themes (steps $4 \& 5$ ), followed by writing up results (step 6).

\section{Results}

The stories included episodes of repeated levels of physical violence alongside prolonged coercive control, and financial abuse. Violence was sustained over at least three years with the maximum reported at thirty-five years. Analysis uncovered symptoms of CPTSD across the survivors' stories. Four themes, with associated sub-themes were identified (see Table 1). TABLE 1 ABOUT HERE

\section{Theme 1. Difficulties in affect regulation}

The emotional impact of abuse was evident. The women responded via protective yet destructive emotional responses that were aimed inwardly through suicidal ideation and selfharm and outwardly through anger towards the perpetrator.

\section{Suicidal ideation}

The women described intense emotional responses to the abuse and abuser that resulted in suicidal ideation and self-harming behaviours. Self-harming behaviours were a response to the prolonged abuse and taking one's life was a way out of the relationship. Selfharm is often a way of regulating emotions and managing overwhelming experiences. For some women inability to practice affect regulation was evidenced by suicide attempts as seen with Participant 4 (age 52) "I'd gone, I tried to commit suicide" and again with Participant 6 
(age 58) 'I'd attempted to take me own [life] and I think it was the hospital that got them [women's service] in touch with me, 'cause they were worried". Suicidal ideation and suicide attempts were common among the narratives of the women. At times they were followed by an emotional numbing which resulted in a lack of activity in the days following attempts to taking their own life: "Tried to commit suicide...didn't come out of my flat for three days" (Participant 5, age 53). Other forms of affect regulation accompanied the suicide attempts, which included other types of self-harm and abstaining from eating food.

"I actually attempted suicide and told him goodbye everything... so I ended up living with him and his mother, coz I'd actually attempted to slit my wrists... not being able to tell anybody so I started self-harming but I managed to keep that secret as well and I stopped eating, you know I would only eat when I absolutely had to and if I was eating anything I'd told myself I'm only eating coz I've got the baby” (Participant 11, age 45).

\section{Modulation of anger}

A further symptom of problematic affect regulation was modulation of anger. For some women, this aggression was internalized through intense feelings toward the abuser often due to a sense of being stuck within the relationship. In this way, living with physical and psychological torture resulted in the development of a protective strategy associated with the 'fight or flight' trauma response. One participant described wishing death upon her partner as way of getting out of the relationship and having some 'peace':

"I used to look at him and think I wish you were dead, he used to walk past me, and

I'd think die, just leave me in peace... I mean I wish him dead anyway so the sooner the better" (Participant 3, age 63).

Other participants' anger was expressed through violent outbursts at their abuser, in response to the violence they had received. One woman described violent expression as a form of self- 
defence: "It just escalated from there, and at first it was like don't you dare do that to me cos I'll hit you back" (Participant 4, age 52). Another participant tells how she violently responded to her abuser and described intense feelings of wanting to physically harm and hurt him: "I wanted to scratch his eyes out, I was hitting him, I really was, I was going berserk, really, really wanted to hurt him" (Participant 7, age 48).

Emotional dysregulation for these women was linked to intense feelings of anger towards their perpetrator, and was displayed as violent thoughts, threats and physical responses. An inability to regulate emotions of anger, shame, and fear was present for the women in our study in their attempts to manage traumatic experiences. It is considered that such challenges with affect regulation will be present in other relational encounters, including the therapy dynamic.

\section{Theme 2: Belief systems that erode self-determination}

Participants illustrated how the abusive behaviours became intrinsic to their relationship. Coupled with their own view of themselves as responsible for the abuse taking place, this led women to normalise abusive behaviours and blame themselves. Some examples are suggestive of the way in which coercive control from their partner contributed to an erosion of their self-worth or capacity to view their relationship from a place of selfdetermination. In most cases, their pre-relationship belief systems regarding what a healthy relationship looked like and about themselves as being at fault when relationships went wrong, were then further enhanced by their partner's controlling behaviours. This sense of responsibility for what had happened to them made it difficult for women to seek support from others based upon the belief that they would be the one who would be shamed for what had been done to them.

\section{This is the norm}


Participants disclosed a level of acceptance of relationships based upon previous beliefs about what a good relationship looks like. Participant 1 illustrates how behaviours that could be considered to erode self-determination are initially perceived and accepted as acts of love and therefore accepted as the norm:

"You think if that's the person that loves you so you think that, well, maybe that is the way... what he'd say was 'Aw, look I'll deal with all the bills, I'll do all that cause it takes the pressure off you'... Yeah, so you think he's being they're being nice to do that" (Participant 1, age 49).

Participant 2 (age 45) emphasises early life messages indicating that she ought to remain in the marriage alongside a family norm not to have self-determination in a relationship. Therefore the concept of accessing support becomes unthinkable as it conflicts with the need to comply:

"The way I was brought up was that once you're married, you're married for life... and you do whatever your husband says or does ...so I thought I'd have to just stick with it, and I didn't know... any support I could seek".

Consideration that this was abuse is absent in the following quotes and gives an indication of earlier experiences/beliefs about relationships that make recognition very difficult. Furthermore, it is possible that time and familiarity contributed to the view that this relationship was typical. Participant 1 (age 49) describes not recognising the behaviours as abusive, "I never recognised what he was doing to me was wrong, I still don't". This is similar for Participant 4, who describes that sort of behaviour as normal, "It's normal...for home life to be like, so I just get on with it”. Normalising was echoed by Participant 7 (age 46) who remained in the relationship, "I stayed because it was the norm".

\section{I am at fault}


A sense of worthlessness and self-blame was present. Participants' belief in themselves had been eroded. The long-term impact of IPV influenced their ability to maintain self-determination and to seek support from others as the shame was compounded by beliefs that they were at fault. Participants identified that being judged was a contributing factor to their lowered self-worth and belief that they were the one to blame:

"He used to just doubt on me all of the time and I used to believe it, I used to believe everything that he said to me, and it was horrible... he dragged me down until I was that small [hand gesture]" (Participant 5, age 53).

Feelings of worthlessness and self-blame are evidenced by their belief that being at fault was intrinsic to who they were or how they behaved. Participant 2 (age 45) reflects on herself as an 'easy target' in terms of making sense of the abuse, "I was an easy target...I think if I was more strong-minded or strong willed it might have been different". Self-blame is also evident for Participant 5 (age 53) "I blame myself for what happened. I mean to me it just seems to never end I feel as if what am I doing wrong in life for people to do these things to me".

Shame, which was linked to how the women felt they (and not the perpetrator) would be viewed by others, was instrumental to not summoning the self-determination to seek support from others.

"I couldn't explain at all what was going on because for me it meant that I was failing... I was failing to be loved and I was failing in the marriage and I was failing as a human so I needed to try really, really harder... and just do more because I clearly was failing so I needed to do more" (Participant 10, age 53).

"I thought they are not going to believe what I say...I was embarrassed, I was ashamed of what he was making me do" (Participant 12, age 52).

Self-worth had become eroded to such a degree that the women integrated the perpetrator's messages that they were at fault and therefore, to blame for what was happening to them. 


\section{Theme 3: Managing the threat response}

Threat responses were evident due to participants experiencing cognitive and physiological responses that were dissociative in nature in addition to finding ways of diminishing what was a highly threatening and consequently risky, situation. In some instances, their threat response provided them with a way of coping with the traumatic experiences they were exposed to with the aim of keeping themselves and others safe.

\section{Dissociating}

Participants referred to their brain 'shutting down'. This part of the body symbolised the place where their distress was stored and there appeared to be a need for either removing themselves from what they were experiencing, or they found it difficult to access the information because it was just too painful.

"I thought, I can go back and he can batter me head in, I'll blank him out, and you think of all the other ways of getting round... me head was mashed, I mean when I sat with the solicitor and she said 'tell me what's happened', I said I can't, I said if I could open me [sic] head, I'd let you see what he's done to me" (Participant 3, age $63)$.

"It was, because I had problem, when I talk to people, a certain people my brain shuts down and I can't think of one word to say... and then I thought, how can you not remember where you've been ... and that frightened me... and I started getting flashbacks and things" (Participant 12, age 52).

Dissociation was evident in the form of memory loss whereby participants struggled to recall details or trust that their memory was a reliable source, "Two and a half, probably three years ago, something like that, now coz my mind had just blocked everything, everything out" (Participant 4, age 52). Participant 10 (age 53) also described her memory as not being real: 
'You know and you don't want to talk about it coz it's not that people don't believe you it's just that...your memory of it is not real”.

Finally, dissociation was present in the form of derealisation. Participant 9 (age 55) felt detached from her own experience which began following childhood sexual abuse:

"Yeah I've just got to do it...I can't, like, go out the house I've just gotta say I was sexually abused as a child...you know the more you say it, the more...real it is. Coz sometimes you don't think it was real...you think was it a dream. Did I dream it? It felt real".

\section{Diminishing the risk}

To manage the threat, participants had a heightened response to their environment, the perpetrator, and those around them. Years of abuse led them to be vigilant to any potential physical or interpersonal threat to reduce any potential risk of harm to others or themselves. For Participant 1 (age 49) this was in relation to protecting her children: "Making sure that they're alright, getting them up to go to college, if they're at college, making sure they phone...not saying I want to know where they are but make sure you are okay”. Participant 2 (age 45) recalled her experiences of attempting to diminish the risk of the perpetrator harming her, revealing the responsibility she felt:

"I started getting a bit like, jittery because then once the kids were out, it was just like me and him and I would be wary of what I was doing or...if I was like washing dishes, like, how much noise I was making”.

The way Participant 5 (age 53) felt others viewed her at the time of the abuse led her to become extra vigilant that she used avoidance strategies to manage this threat:

“I am starting to see it all now but years ago...I wouldn't even have stepped out my door...I used to hide, because I felt as if everybody knew about me and that wasn't the case it was just my mind ticking over". 
Dissociation became a defensive coping mechanism to protect the women from the horror of their torture from their intimate partner. The assessment and management of risk became fundamental to survival in an unpredictable, frightening, and unsafe world.

\section{Theme 4. Difficulties in sustaining relationships}

A further consequence was discussed in terms of sustaining open and honest relationships with others. The impact of this extended beyond relationships with intimate partners to the inability to form secure friendships and meaningful relationships with family, friends, and healthcare workers based upon mistrust and the need to conceal.

\section{Concealment}

Participants identified the need to hide things from others to protect themselves from being judged or harmed. Participant 10 (age 53) recounted how she found it difficult to confide in others, as she worried what they would think about her relationship:

"You do keep it to yourself, I mean, you have a friend that you sort of say things to, but you don't wanna divulge too much, do you, coz you don't want them to think, oh my God she's not very happy there"

Similarly, another participant described the negative impact with her own family and how challenging it was for her to seek support at the time, "I made some friends, and you know, I talked to them about it. [...] I couldn't tell, like, my own family or [...], and nobody in his side of the family" (Participant 2, age 45). Some participants told of how being in an abusive relationship had impacted negatively on their ability to form and sustain other relationships, "It was very rare that I was allowed to have friends and I only had sort of two friends, and they didn't have a clue what was going on in my life, no one did"_(Participant 12, age 52). Distancing from others was another strategy, "I sort of distanced myself away from them all [my sisters]" (Participant 9, age 55). Although participant 2 (age 45) now recognised that 
support was available, concealment became her preferred option due to her belief about herself as 'private';

"I think if I did know about those places or people you can talk to counselling or anything like that just to get it off your chest, but I'm also a private person so when it was happening, I just liked to keep it to myself".

\section{Mistrust}

Trusting other people was described by some participants as a significant problem relating to the formation and maintenance of close relationships and enabling potential support, "I don't trust my friends" (Participant 13, age 51). Mistrust was based on the belief that they would tell other people what was happening, "I would have if I knew there wasn't anything in it...like gossip or that they would tell someone else” (Participant 2, age 45), or that they would not be believed, and the process was shameful, "I thought they are not going to believe what I say and plus...I was embarrassed, I was ashamed of what he was making me do" (Participant 12, age 52). Furthermore, Participant 6 (age 58) identified how much support was being offered but how she could not accept it:

"She [GP] squeezed my hand and said please talk to me...she said I have taken your mobile number she said if you don't make this appointment, I will ring you she said but you have to talk to me she said I can't do anything unless you talk to me and I said ok and I cancelled the appointment".

Being prevented from being close to others and therefore not having any opportunity to build trusting relationships resulted in Participant 11 (age 45) feeling isolated and having no sources of social support: 
"I didn't have anybody to talk to or turn to, so the isolation was horrendous. I was literally living on the streets, I had no help, no friends or anything, I'd been talking to some of the mothers in the village, but I thought I can't ask anybody for anything'.

Concealment of IPV itself is likely to be a survival mechanism as it is often too dangerous to tell anyone. The shame and sense that others may be judgemental compounds this concealment because of an inability to trust others. Consequentially isolation is reinforced, help is not sought, and the woman continues to believe that relationships cannot and will not be safe for her.

Trust is an important part of relationship formation and maintenance. For women who have sustained prolonged abuse, trust has been shattered and the self is viewed as faulty. Therefore, relationships are approached with caution. Sometimes this can be exacerbated by a state of hypervigilance; the feeling of being under constant threat is a learned response. Emotional recognition and regulation become particularly challenging and may result in destruction towards the self or a wish to destroy the perpetrator. The survivors disclosed many violations, yet these had become accepted as a 'normal' part of the relationship. Equally, the women were reluctant to disclose for fear of being judged or their trust being further broken, and this led to concealment and isolation. Overall, the risk that these experiences would further compound mental health was high as mid-life to older women showed reluctance to seek support at a time when they needed it the most.

\section{Discussion}

The purpose of the study was to explore the presence of symptoms of CPTSD in the stories of mid-life to older women who had survived IPV. Survivors provided a narrative of their experiences which allowed individuals time to reflect on their experiences and discuss specific aspects of their story that were salient to them. Narratives allow common language about experiences of distress to be explored, help to provide meaning and context, and create 
a foundation for the journey of recovery (Johnstone \& Boyle, 2018). Therefore, considering the narratives of survivors through a trauma-focused lens allows the impacts and consequences of the trauma to be understood as it makes sense to the survivor. Four core themes were identified: difficulties in affect regulation, belief systems that erode selfdetermination, managing the threat response, and difficulties in sustaining relationships. The findings suggest that underlying symptoms of CPTSD were present which provides a framework for therapeutic practitioners to consider when working with clients with IPV histories.

The emotional impact of prolonged abuse was evident. Participants described scenes of intense emotional dysregulation that resulted in aggression towards the perpetrator and damaging behaviours towards themselves in the form of suicide attempts and self-harm. Problems with affect regulation, including anger, have been identified as a symptom of complex trauma (Pill et al., 2017; Sweeney \& Taggart, 2018) and as 'emotion regulation difficulties' within the ICD-11 (Cloitre, 2020, p.130). Violence towards the perpetrator was described as thoughts (wanting him to die) and behaviours (violent outbursts). For many survivors, anger plays a key role in the recovery process but if it is not identified as a response to trauma it can lead to victim blaming which can be detrimental to the recovery process. Links between poor mental health and domestic abuse have been identified for older women including suicide risk which was evident for some of the women in our study. The clinical utility of this finding is important as behaviours such as emotional and relationship instability, unstable self-concept, and impulsive and self-harm related coping strategies align with other diagnostic disorders such as BPD (Courtois, 2004); however, our findings suggest this may be a trauma response. The importance of assessing for risk of suicide and self-harm among survivors of IPV has been identified within the literature (e.g., Munro \& Aitken, 
2020). Our findings also suggest that practitioners can recognise this symptom as a trauma response to provide the most appropriate treatment.

The women in our sample had all been in long-term abusive relationships; some had multiple abusive partners, and most women disclosed childhood abuse. Sustained abuse impacts on a person's belief system and creates a negative self-concept; this symptom of complex trauma (Cloitre, 2020; Sweeney \& Taggart, 2018) was displayed in terms of eroded belief systems among the participants. Women identified early childhood experiences with abuse and family discourse contributing to normalising IPV. Normalising abuse is common among survivors and is detrimental to help seeking, particularly among older adults who are often more willing to accept abuse to maintain the family unit (Carthy \& Taylor, 2018).

Also linked to participants' belief systems and self-evaluation was the belief that they were to blame. Again, this is common among survivors of abuse but can be exacerbated for those who are older by generational understandings of gendered roles (Beaulaurier et al., 2008). However, such findings minimise the psychological impact of identity alterations and the importance of this on a person's recovery process. Cognitive dissonance is a way of explaining those emotion-focused strategies that occur through normalisation and self-blame (Nicholson \& Lutz, 2017). Prolonged abuse can contribute to more severe cognitive alterations and is an important aspect to consider in therapeutic work. Understanding the trauma journey helps to see the interaction between cognitive dissonance and the erosion of self-determination.

Participants described further alterations in their cognitive processes in relation to managing the threat response. Dissociation as a defence mechanism for managing prolonged trauma is likely to present itself in the therapeutic relationship and may be experienced as unsettling as the client moves between realities. The recognition of dissociation as a symptom of trauma is essential in the non-pathologizing of trauma-related outcomes to avoid further 
shame, isolation, and fear that may be associated with diagnosis and labelling. Participants' efforts to manage threat responses are illustrated by the PTSD aspect of CPTSD in which there is a persistent sense of current threat and inability to recall aspects of the event(s) (American Psychiatric Association, 2013). High levels of hypervigilance that are frequently activated by interpersonal dynamics are likely to be one way that this threat response is experienced.

The final theme illustrated that difficulties in sustaining relationships and forming close attachments with others came from a place of mistrust and resulted in the concealment of their experiences. For example, in individuals who have experienced severe trauma, it is not shame which directly affects relationship difficulties, but rather the responses to managing those feelings such as withdrawal and avoidance (Dorahy et al., 2013). Fleming \& Resick (2016) propose that PTSD-related dissociation is explained more by one's thinking in response to an event rather than the event itself and is associated with an avoidant coping response, during the event and subsequently. Survivors of IPV often experience dissociation as a coping strategy (Miller, 2017), and the connection between dissociation and relationship difficulties supports concepts of dissociation as an interpersonal construct (Lyons-Ruth, 2003). Individuals with higher levels of dissociation are more inclined to experience fear and uncertainty regarding relationships (Dorahy et al., 2013). Building social networks can become an important protective factor in facilitating the recovery process and improving selfesteem and well-being for survivors (Heywood et al., 2019). Therefore, therapeutic treatment for this client group may need to consider ways of developing or enhancing healthy support systems in the community.

\section{Implications and conclusions}

Complexities are inherent in working with mid-life and older help-seeking female survivors of long term IPV displaying poor emotional regulation due to physiological arousal 
associated with threat. These impact on the development of safety and trust within the therapeutic relationship, engagement, and the ability to tolerate distress associated with trauma-focused interventions. Hesitancy to disclose IPV is often due to the shame felt by the survivor which is exacerbated by feelings of being at fault and negative reactions by others. Clinically, this finding supports the importance of validating a client's experiences and ensuring they feel safe within the therapeutic relationship. Furthermore, women can be placed at greater risk of harm from the perpetrator when they leave an abusive relationship. Training to ensure staff can respond in a supportive manner to disclosures of abuse is important to meeting clinical needs (WHO, 2020). Longer-term therapy is indicated by the need for the women to build trust, feel safe, and build the 'ego strength' to tolerate emotional exposure both within and beyond the therapeutic space. Furthermore, therapy may be compromised by their inability to tolerate the closeness of the relationship and because of their creative and protective 'defences' which may lead to difficulties in engaging with the therapeutic process; understanding what has contributed to difficult experiences, placing emphasis upon a formulation of difficulties rather than a diagnosis, is important (Connors, 2018).

Clinicians need to account for the experiences of dissociation (which may or may not be a consequence of re-experiencing), including an individual's capacity to cognitively engage in therapeutic work. Our findings suggest that when working therapeutically with midlife and older female IPV survivors' clinicians should also be aware of the potential presence of CPTSD. Courtois (2004) provides guidance for the assessment of complex trauma. This includes the importance of showing respect to the client when acknowledging that disclosing past or current trauma can be very difficult and paying attention to the presentation of the client both during and after the session to ensure that any disclosure is regulated so as not to overwhelm. Acknowledgment of the emotional pain associated with 
disclosure is key to ensuring that the client feels safe and contained as they share traumatic material (Courtois, 2004).

Our findings demonstrate that for midlife and older female survivors of IPV it is important to work in a trauma-informed way where the emphasis is on what happened rather than what is wrong, consistent with the PTMF (Johnstone \& Boyle, 2018). Mid-life and older female survivors have experienced a loss of power within an intimate relationship that has been sustained over a long period of time, which links with the 'belief systems that erode self-determination' theme within our findings. The power aspect of the model can help the therapist and client explore how self-blame and acceptance of abuse have become features of that power imbalance. Threat within the relationship is also addressed in terms of how the loss of power can impact on relationships and a person's sense of self. Difficulties in affect regulation concern the challenges faced by survivors in coping with their own emotional response to events around them, often because they have been surviving a highly threatening situation and continue to do so, when the relationship has ended. The strategies to manage this threat, that our findings have identified, relate to the themes of 'difficulties in affect regulation' and 'managing the threat response', which clinicians and clients can work through within the threat part of the framework. Finally, the 'difficulties in sustaining relationships' theme would be tackled within the meaning aspect of the PTMF, which relates to a person's belief system and how they develop meaning in a way that enables them to form new relationships. For the women in our sample, reduced levels of trust were prevalent when discussing relationships with others, therefore the meaning aspect of the framework provides a space to work through and make sense of the barriers to forming new trusting relationships.

Despite the contribution of our findings to understanding how CPTSD may be presented in the stories of IPV among mid-life and older women and the implications of this for therapeutic practice, there are some limitations to consider. The interviews coded in this 
study were not directly gathered for the purpose of exploring CPTSD. However, what they do offer are examples of how symptoms of CPTSD are present in the life stories of IPV survivors. This provides a framework for further exploration, and for practical applications that can be implemented in training and practice. A further point to note is that all participants were recruited through domestic violence specialist services and were receiving varying levels of support. Therefore, caution needs to be given to generalising the findings and conclusions of this research to all older survivors of domestic violence. There are many people experiencing IPV who do not seek support and therefore further research, policy, and practice should focus on how to engage and support those at risk. Yet the findings and conclusions of the current study will be useful to practitioners and services working therapeutically with mid-life and older help-seeking female survivors of IPV.

\section{References}

American Psychiatric Association. (2013). DSM. Fifth Edition. USA: American Psychiatric Association Publishing.

Beaulaurier, R.L., Seff, L.R. \& Newman, F.L. (2008). Barriers to help-seeking for older women who experience intimate partner violence: A descriptive model. Journal of Women \& Aging, 20(3/4), 231-248. doi: 10.1080/08952840801984543

Braun, V. \& Clarke, V. (2006). Using thematic analysis in psychology. Qualitative Research in Psychology, 3(2):77-101. doi:10.1191/1478088706pq063oa

Briere, J. \& Spinazzola, J. (2005). Phenomenology and psychological assessment of complex posttraumatic states. Journal of Traumatic Stress, 18(5), 401-412. doi:10.1002/jts.20048

Carthy, N.L. \& Taylor, R. (2018). Domestic violence in women over 45: A UK practitioners perspective. European Journal of Criminology.15(4), 503-519. doi:10.1177/1477370817749484 
Cloitre, M. (2020). ICD-11 complex post-traumatic stress disorder: simplifying diagnosis in trauma population. The British Journal of Psychiatry, 216, 129-131. doi:

10.1192/bjp.2020.43

Connors, K, J. (2018). Dissociative and complex trauma disorders in health and mental health contexts: Or why is the elephant not in the room?, Journal of Trauma \& Dissociation, 19:1, 1-8. doi: 10.1080/15299732.2018.1379855

Courtois, C. A. (2004). Complex trauma, complex reactions: assessment and treatment. Psychotherapy: Theory, Research, Practice, Training, 41(4), 412-425. Doi: $10.1037 / 0033-3204.41 .4 .412$

Crossley, M. L. (2000). Introducing Narrative Psychology: self, trauma and the construction of meaning. Milton Keynes: Open University Press.

Dekel, R., Shaked, O., Ben-Porat, A, Itzhakay, H. (2019). The inter-rationas of physical and mental health: self-rated health, depression, and PTSD among female IPA survivors. Violence Against Women, 379-394. doi:10.1177/1077801219832916

Dokkedahl, S., Kristensen, T. R., Murphy, S. \& Elklit, A. (2021). The complex trauma of psychological violence: cross-sectional findings from a Cohort of four Danish women shelters. European Journal of Psychotraumatology, 12(1), 1-13. doi:

$10.1080 / 20008198.2020 .1863580$

Dorahy, M. J., Corry, M., Shannon, M., Webb, K., McDermott, B., Ryan, M. \& F.W. Dyer, K. (2013). Complex trauma and intimate relationships: The impact of shame, guilt and dissociation. Journal of Affective Disorders, 147(1), 72-79.

doi:10.1016/j.jad.2012.10.010

Ford, J. D. \& Courtois, C. A. (2014). Complex PTSD, affect dysregulation, and borderline personality disorder. Borderline Personality Disorder and Emotion Dysregulation, 1(9), 1-17. doi: 10.1186/2051-6673-1-9 
Herman, J. L. (1994). Trauma and recovery: The aftermath of violence--from domestic abuse to political terror. London, UK: Rivers Oram Press.

Heywood, I., Sammut, D. \& Bradbury-Jones, C. (2019). A qualitative exploration of 'thrivership' among women who have experienced domestic violence and abuse: Development of a new model. BMC Women's Health, 19(1), 106-15. doi:10.1186/s12905-019-0789-Z

Home Office. (2015). Controlling or Coercive Behaviour in an Intimate or Family Relationship. Statutory Guidance Framework. Retrieved from https://assets.publishing.service.gov.uk/government/uploads/system/uploads/attachment _data/file/482528/Controlling_or_coercive_behaviour_-_statutory_guidance.pdf

Hopchet, M., Kholti, S. \& Vanhelleputte, A. (2017). Effects of interpersonal violence: Complex trauma, symptomatic evolution and therapeutic implications. Annales MedicoPsychologiques, 175(3), 290-293. doi:10.1016/j.amp.2017.01.007

Howard, L.M., Trevillion, K. \& Agnew-Davies, R. (2010). Domestic violence and mental health. International Review of Psychiatry, 22 (5), 525-534. doi: $10.3109 / 09540261.2010 .512283$

Johnstone, L. \& Boyle, M. with Cromby, J., Dillon, J., Harper, D., Kinderman, P., Longden, E., Pilgrim, D. \& Read, J. (2018). The Power Threat Meaning Framework: Towards the identification of patterns in emotional distress, unusual experiences and troubled or troubling behaviour, as an alternative to functional psychiatric diagnosis. Leicester: British Psychological Society.

Karatzias, T., Cloitre, M., Maercker, A., Kazlauskas, E., Shevline, M., Hyland, P., Bisson, J.L., Roberts, N.P. \& Brewin, C.R. (2018). PTSD and Complex PTSD: ICD-11 updates on concept and measurement in the UK, USA, Germany and Lithuania. European Journal of Psychotraumatology, Vol. 8. doi: 10.1080/20008198.2017.141810 
Kulkarni, J. (2017). Complex PTSD - a better description for borderline personality disorder? Australasian Psychiatry, 25(4), 333-335. doi: 10.1177/1039856217700284

Lawson, D.M., Davis, D. \& Brandon, S. (2013). Treating complex trauma: critical interventions with adults who experienced ongoing trauma in childhood. Psychotherapy, 50(3), 331-335. doi: 10.1037/a0032677

Litvin, J. M., Kaminski, P. L. \& Riggs, S. A. (2017). The complex trauma inventory: A selfreport measure of posttraumatic stress disorder and complex posttraumatic stress disorder. Journal of Traumatic Stress, 30(6), 602-613. doi:10.1002/jts.22231

Lyons-Ruth, K. (2003). Dissociation and the parent-infant dialogue: A longitudinal perspective from attachment research. Journal of the American Psychoanalytic Association, 51(3), 883-911. doi:10.1177/00030651030510031501

Miller, A. (2017). Dissociation in families experiencing intimate partner violence. Journal of Trauma \& Dissociation, Issue 3: The Abused and the Abuser: Victim-Perpetrator Dynamics, 18(3), 427-440. doi:10.1080/15299732.2017.1295425

Miller, M. W. \& Resick, P. A. (2007). Internalizing and externalizing subtypes in female sexual assault survivors: Implications for the understanding of complex PTSD. Behavior therapy, 38(1), 58-71. doi: 10.1016/j.beth.2006.04.003

Munro, V. E. \& Aitken, R. (2019). Form hoping to help: Identifying and responding to suicidality amongst victims of domestic abuse. International Review of Victimology, 26, 29-49. doi: 10.1177/0269758018824160

Nelson, H.N., Nygren, P., McInerney, Y. \& Klein, J. (2004) Screening Women and Elderly Adults for Family and Intimate Partner Violence: A Review of the Evidence for the U.S. Preventive Services Task Force. Annals of Internal Medicine, 140 (5), 387-404. doi: 10.7326/0003-4819-140-5-200403020-00015

Nicholson, S. B. \& Lutz, D. J. (2017). The Importance of Cognitive Dissonance in 
Understanding and Treating Victims of Intimate Partner Violence. Journal of

Aggression, Maltreatment \& Trauma, 26(5), 475-492, doi:

$10.1080 / 10926771.2017 .1314989$

Pathak, N., Dhairyawan, R. \& Tariq, S. (2019). The experience of intimate partner violence among older women: a narrative review. Maturitas, 121, 63-75.

doi:10.1016/j.maturitas.2018.12.011

Pill, N., Day, A. \& Mildred, H. (2017). Trauma responses to intimate partner violence: A review of current knowledge. Aggression and Violent Behavior, 34, 178-184. doi:10.1016/j.avb.2017.01.014

Schackner, J.N., Weiss, N.H., Edwards, K.M., Sullivan, T.P. (2017). Social reactions to IPV disclosure and PTSD symptom severity: assessing avoidant coping as a mediator. Journal of Interpersonal Violence, 36(1-2), 508-526.

https://doi.org/10.1177/0886260517727493

Substance Abuse and Mental Health Services Administration (2014). SAMHSA's Concept of Trauma and Guidance for a Trauma-Informed Approach (HHS Publication No. (SMA) 14-4884). SAMHSA. Retrieved from https://www.nasmhpd.org/sites/default/files/ SAMHSA_Concept_of_Trauma_and_Guidance.pdf

Sweeney, A. \& Taggart, D. (2018). (Mis)understanding trauma-informed approaches in mental health. Journal of Mental Health, 27(5), 383-387. doi:

$10.1080 / 09638237.2018 .1520973$

Van der Kolk, B. (2000). Posttraumatic stress disorder and the nature of trauma. Dialogues in Clinical Neuroscience, 2(1), 7-22. Retrieved from https://www.ncbi.nlm.nih.gov/ pmc/articles/PMC3181584/ 
Walby, S. and Allen, J. (2004). Domestic violence, sexual assault and stalking: findings from the British Crime Survey. Home office research study 276. Retrieved from http://nomsintranet.org.uk/roh/official-documents/HomeOfficeResearchStudy276.pdf World Health Organisation [WHO]. (2018). International Statistical Classification of

Diseases and Related Health Problems, $11^{\text {th }}$ Revision (ICD-11). Geneva: WHO. Retrieved from https://www.who.int/classifications/icd/en/

World Health Organization [WHO] (2020). United Nations Population Fund (UNFPA), United Nations High Commissioner for Refugees (UNHCR). Clinical management of rape and intimate partner violence survivors: developing protocols for use in humanitarian settings. Geneva: WHO. Retrieved from https://apps.who.int/iris/bitstream/handle /10665/331535/9789240001411-eng.pdf

Table 1. Theme summary table

\begin{tabular}{|c|c|c|}
\hline Theme & Subtheme & Definition \\
\hline \multirow[t]{2}{*}{$\begin{array}{l}\text { Difficulties in affect } \\
\text { regulation }\end{array}$} & Suicidal ideation & $\begin{array}{l}\text { Emotional responses to the abuse } \\
\text { included suicidal ideation and self- } \\
\text { harming behaviours. }\end{array}$ \\
\hline & Modulation of anger & $\begin{array}{l}\text { Affect regulation focused on internal and } \\
\text { external aggression. }\end{array}$ \\
\hline \multirow{2}{*}{$\begin{array}{l}\text { Belief systems that } \\
\text { erode self- } \\
\text { determination }\end{array}$} & This is the norm & $\begin{array}{l}\text { Acceptance of relationship and } \\
\text { normalising of abuse. }\end{array}$ \\
\hline & I am at fault & $\begin{array}{l}\text { Believing the abuse was their fault } \\
\text { resulted in eroded self-belief and shame. }\end{array}$ \\
\hline \multirow{2}{*}{$\begin{array}{l}\text { Managing the threat } \\
\text { response }\end{array}$} & Dissociating & Physiological dissociative responses. \\
\hline & Diminishing the risk & $\begin{array}{l}\text { Extra vigilance to any physical or } \\
\text { interpersonal threat as a way of } \\
\text { protecting self. }\end{array}$ \\
\hline \multirow[t]{2}{*}{$\begin{array}{l}\text { Difficulties in } \\
\text { sustaining relationships }\end{array}$} & Concealment & $\begin{array}{l}\text { Hiding things from others to protect } \\
\text { against judgement or interpersonal harm. }\end{array}$ \\
\hline & Mistrust & $\begin{array}{l}\text { Problems with trusting others close to } \\
\text { them. }\end{array}$ \\
\hline
\end{tabular}

